\title{
Physicians' and patients' expectations of therapies for pulmonary arterial hypertension: where do they meet?
}

\author{
Luke S. Howard', Pisana Ferrari² and Sanjay Mehta ${ }^{3,4}$
}

\begin{abstract}
Affiliations: 'Dept of Cardiac Sciences, National Pulmonary Hypertension Service, Hammersmith Hospital and Imperial College London, London, UK. ${ }^{2}$ Pulmonary Hypertension Association Europe, Vienna, Austria. ${ }^{3}$ Pulmonary Hypertension Association of Canada, Vancouver, BC, Canada. ${ }^{4}$ Dept of Medicine, Division of Respirology, Southwest Ontario PH Clinic, London Health Sciences Centre, Schulich School of Medicine, Western University, London, ON, Canada.
\end{abstract}

Correspondence: Luke S. Howard, Dept of Cardiac Sciences, National Pulmonary Hypertension Service, Hammersmith Hospital, Imperial College Healthcare NHS Trust, Du Cane Road, London, W12 OHS, UK.

E-mail: L.howarddimperial.ac.uk

ABSTRACT In recent years, many new, effective therapies for pulmonary arterial hypertension (PAH) have become available and are widely used, yet the long-term prognosis for patients with PAH remains poor. In the absence of a cure, physicians' expectations of $\mathrm{PAH}$-specific therapies are to: 1) improve patients' symptoms and functional capacity; 2) slow disease progression; and 3) improve survival. However, patients with $\mathrm{PAH}$ may prioritise other more tangible needs, such as improvements in their ability to carry out their daily tasks and increase their quality of life. Patients with PAH have also called out for social and emotional support from their physicians, caregivers, families and patient associations. Therefore, it is necessary that clinical trials of PAH-specific treatments include end-points that are meaningful to both patients and physicians, and that a multidisciplinary approach to the management of patients with $\mathrm{PAH}$ takes into consideration the broader aspects of patients' and caregivers' needs and wishes beyond simple physiological measurements.

0 @ERSpublications

Treatment and management goals for pulmonary arterial hypertension: meeting both physicians and patients expectations http://ow.ly/Cuezv

\section{Introduction}

Pulmonary arterial hypertension (PAH) is a progressive disease of the small pulmonary arteries, with increasing mean pulmonary vascular resistance eventually leading to right ventricular failure $[1,2]$. The disease is heterogeneous and, although idiopathic PAH is the most common diagnosis in registries [3-5], $\mathrm{PAH}$ can also be heritable, induced by drugs or toxins, or associated with conditions such as connective tissue disease, congenital heart disease, portal hypertension, HIV infection or schistosomiasis [6]. Initial diagnosis can be difficult as patients often present with non-disease-specific symptoms such as breathlessness, fatigue, peripheral oedema, chest pain during exertion, light headedness, syncope and abdominal distension $[7,8]$.

Our knowledge of the epidemiology of PAH and indicators of patient prognosis has vastly improved over the past three decades with information coming from both observational patient registries and clinical trial data. PAH is a rare disease with an estimated prevalence of 7-52 cases per million [3, 4, 9-12]. The annual

Received: Aug 292014 | Accepted after revision: Sept 302014

Conflict of interest: Disclosures can be found alongside the online version of this article at err.ersjournals.com

Provenance: Publication of this peer-reviewed article was sponsored by Actelion Pharmaceuticals Ltd, Allschwil, Switzerland (principal sponsor, European Respiratory Review issue 134).

Copyright OERS 2014. ERR articles are open access and distributed under the terms of the Creative Commons Attribution Non-Commercial Licence 4.0. 
incidence of idiopathic PAH in Europe and the USA is 1-2 cases per million [13]. Despite the introduction of many PAH-specific therapies, treatment algorithms [14] and better patient screening [15], mortality associated with PAH remains high with 1-, 3- and 5-year survival rates of $85 \%, 68 \%$ and 57\%, respectively, reported in the US REVEAL (Registry to Evaluate Early and Long-term Pulmonary Arterial Hypertension Disease Management) registry [5, 16]. Similar survival rates have been reported by the French registry, which reported survival rates of $87 \%$ and $67 \%$ at 1 - and 3 -years, respectively [17].

Physicians' expectations of PAH-specific therapies are to provide clinical benefit, including improved symptoms and functional capacity, as well as to slow disease progression and improve survival for their patients. Most of the current PAH-specific medications have been approved on the basis of short-term randomised controlled trials (RCTs) whose primary outcome was increased exercise capacity (as reflected by increased 6-min walking distance (6MWD)), with various secondary outcomes (e.g. pulmonary haemodynamics, New York Heart Association (NYHA) functional class and health-related quality of life (HRQoL)). Clinically, important long-term outcomes (e.g. mortality, institution of parenteral prostanoid infusion, PAH progression and/or right heart failure, and the need for lung transplantation) had not been previously assessed in a RCT until the recent long-term, event-driven trial of macitentan, which demonstrated a significant benefit in a composite morbidity/mortality end-point (primary outcome) of time from initiation of treatment to the first event related to $\mathrm{PAH}$ (worsening of PAH, initiation of treatment with intravenous or subcutaneous prostanoids, lung transplantation or atrial septostomy) or death from any cause up to the end of treatment [18]. It has been suggested by many in the international pulmonary hypertension community that all future PAH-specific therapies must show long-term efficacy in RCTs using clinically relevant end-points of morbidity and/or mortality [19].

In clinical practice, physicians rely on specific treatment goals for the management of their patients, based on end-points that have been shown to be associated with improved survival. These include NYHA functional class assessment, echocardiographic assessment of right ventricle size and function, cardiopulmonary haemodynamics, the 6MWD test, cardiopulmonary exercise testing and biomarkers. Similarly, patients want to live and function better with PAH therapy, but an additional important aim for patients, which should not be ignored, is that they wish to feel better. Previously, assessment of patients' HRQoL as a measure of treatment efficacy in clinical trials or general practice has been limited. However, due to the actions of local and international patient organisations, and more recently health authorities, the views of patients with PAH have been sought and consequently the understanding of the impact of PAH on patients' lives has increased [20,21].

In this review we explore patient expectations and how these may differ from those of their physicians. Clinical evidence for the effect of PAH-specific therapies on outcomes of concern to patients is also discussed.

\section{Goals of therapy in PAH: patient and physician perspectives}

As PAH impacts on several aspects of patients' lives, multiple goals are required of any treatment or care management regimen; however, treatment goals that are important to the patient at a particular point in their life or disease stage may not always overlap with those of their physician (fig. 1). While physicians require treatments for $\mathrm{PAH}$ to reduce the severity of the disease as reflected by, for example, an improvement in cardiopulmonary haemodynamics and markers of right ventricular dysfunction such as $\mathrm{N}$ terminal pro-brain natriuretic peptide plasma levels, patients are usually just as concerned with their overall HRQoL, treatment convenience and the more immediate need for adequate functional capacity to be able to carry out daily activities. A large-scale, international patient and caregiver survey, conducted in late 2011, identified that patients have other needs to address, that are perhaps less obvious to their physicians, such as help with the practical, social and emotional aspects of living with PAH [21]. In this survey more than half of the patients stated that PAH had a "very significant" impact on their daily life (fig. 2) [21, 22], and that they require help with and information on several consequences of PAH and its treatments. These included the impact of the disease on patients' employment and the financial consequences of PAH, the emotional consequences of $\mathrm{PAH}$ such as social isolation, the impact of the disease on personal relationships, and consequent mental health issues such as depression, anxiety and low self-esteem.

In addition, a patient-focused meeting conducted by the US Food and Drug Administration (FDA) in May 2014 discussed the impact of PAH on daily life and gathered patient views on the current available therapies [23]. The FDA recognises the need for a more systematic way to gather insights from patients regarding their disease and available treatment options in order to inform decision-making in the development of novel drugs. The meeting highlighted particular symptoms frequently mentioned by patients; for example, within symptoms of depression and anxiety, patients specified the anxiety of not sleeping at night, demonstrating a need to address insomnia. In addition, with regard to available treatments in general, patients expressed a preference for more convenience with less interference with their daily lives [23]. 


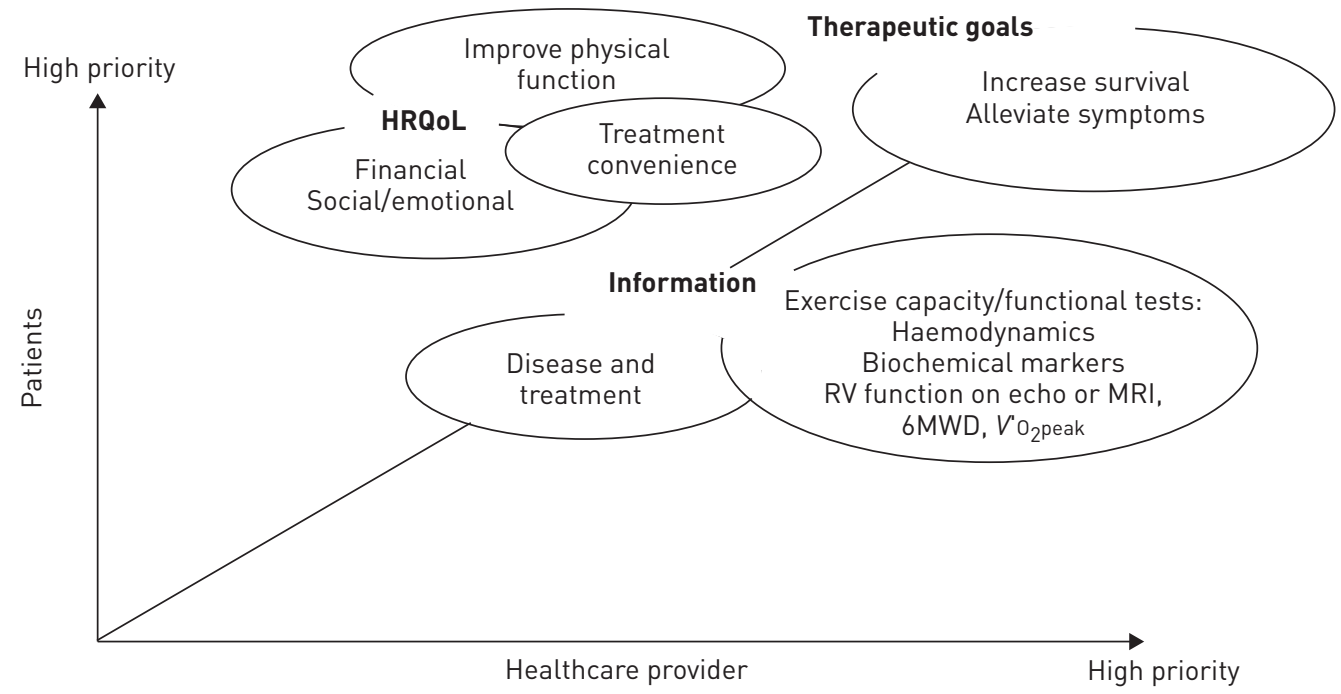

FIGURE 1 Physician and patient goals in the treatment of pulmonary arterial hypertension. HRQoL: health-related quality of life; RV: right ventricular; echo: echocardiography; MRI: magnetic resonance imaging; 6MWD: 6-min walking distance; $V^{\prime} \mathrm{O}_{2}$ peak: peak oxygen consumption.

Similarly, the Canadian Agency for Drugs and Technologies in Health is currently reviewing the clinical and economic impact of newly established PAH therapies, and have requested feedback from patient groups to ensure that the needs of patients are captured within the process [24].

To illustrate the patient's perspective we report details of two patient cases with similar presentations but who have differing outlooks, goals and expectations (table 1). Most physicians might find it "easier" to manage patient A. Although the management of patient B might have failed in the conventional sense, the patient has remained in control of their treatment, possibly even finding it easier to come to terms with the need for intravenous therapy through failure of their chosen strategy. These cases highlight the need for shared decision-making between patients and physicians to ensure that patients' expectations are met, as well as the clinical outcomes set by their physician. Additionally, ensuring that patients' wishes are incorporated when planning treatment goals may lead to greater adherence to treatment [25]. Provided that the patient is well-informed, this may often mean deviating from gold standard treatment guidelines. For example, some patients may find intravenous therapies too intrusive, even decreasing their quality of life [26]. However, as in the case of patient B, patients should be closely monitored to review their goals and ensure that they are being met [27]. Improvements in these regimens and their monitoring should improve HRQoL for patients. In contrast, some patients may be willing to undergo more aggressive treatment management with the use of multiple and more complex, parenteral therapies at the cost of their normal daily routine, in the hope of achieving faster results or greater objective benefit overall. It is therefore necessary to make individual assessments and manage the needs and expectations of both the patient and physician in order to provide a personalised approach to patient care.

\section{Delaying disease progression}

A common goal for patients is to live longer, therefore, the assessment of the effect of PAH therapies on mortality should be an important end-point for clinical studies. However, conducting such trials on mortality alone has limitations as they would require the inclusion of a large number of patients in order to achieve sufficient statistical power. As PAH is a rare disease, the coordination and conduct of such large trials would be very difficult to organise. Instead, in many clinical trials for PAH the assessment of efficacy in terms of clinical worsening has been linked to a combination of disease-related events, including death, hospitalisations for $\mathrm{PAH}$, interventional procedures such as lung transplantation or atrial septostomy, escalation of therapy or any evidence of clinical deterioration based on the patient's functional assessments [19]. Previously, the efficacy of PAH therapies to impact on these outcomes has been consigned to secondary end-points over relatively short duration trials (3-6 months) [28]. However, since the 4th World Symposium on Pulmonary Hypertension [19], several studies on PAH therapies have been designed to evaluate disease progression with combined primary end-points of morbidity and mortality, similar to those seen in other cardiovascular disease trials [28]. Several PAH treatments are associated with their own complications or can otherwise affect patients' HRQoL. For example, hospital stays are feared by patients, as they are uncomfortable and inconvenient. In addition, hospitalisations for $\mathrm{PAH}$ are associated with a worse 


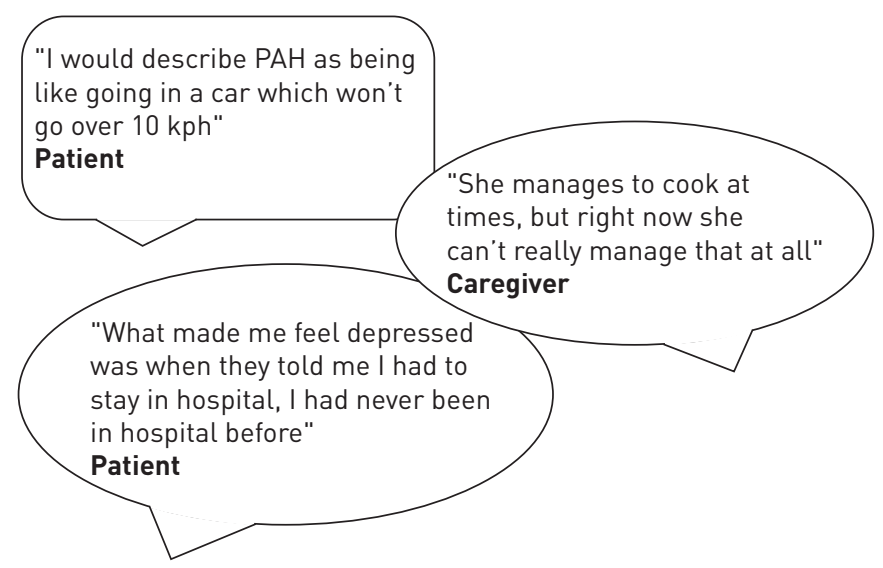

FIGURE 2 Patient and caregiver quotes. PAH: pulmonary arterial hypertension. Reproduced from [22] with kind permission from PHA Europe (www.phaeurope.org).

prognosis [29] and constitute an additional economic burden on both patients and the healthcare system $[30,31]$. Escalation of therapy to i.v. or subcutaneous prostanoid infusion (e.g. epoprostenol or treprostinil) represents an inconvenient development in treatment for patients when compared with oral treatments [32]. In addition, lung transplantation, although curative for $\mathrm{PAH}$, represents a complex surgical procedure that incurs risks associated with the multiple medications used and their cumulative associated side-effects and consequent intensive follow-up [29].

There is limited direct evidence from RCTs of PAH therapies that they lead to a reduction in the risk of mortality. To date, i.v. epoprostenol is the only PAH treatment to have demonstrated a significant reduction in all-cause mortality after 12 weeks of treatment in severe PAH patients (World Health Organization functional class III/IV) in such an RCT [33, 34]. Short-term (3-6 months) improvements in time to clinical worsening, though the definition of this secondary end-point varies between studies, were observed with bosentan (BREATHE (Bosentan Randomized trial of Endothelin Antagonist Therapy)-1) [35], ambrisentan (ARIES (Ambrisentan in Pulmonary Arterial Hypertension, Randomized, Double-Blind, PlaceboControlled, Multicenter, Efficacy Studies)-1 and -2) [36], tadalafil (PHIRST (Pulmonary Arterial Hypertension and Response to Tadalafil)) [37], inhaled iloprost (AIR (Aerosolized Iloprost Randomized Study)) [38] and subcutaneous treprostinil [39]. Combining these trials and others in meta-analyses has shown a reduction in all-cause mortality [40,41]. Moreover, several individual studies have now been completed that assess the long-term disease progression of PAH patients. The SERAPHIN (Study with an Endothelin Receptor Antagonist in Pulmonary Arterial Hypertension to Improve Clinical Outcome) trial was the first to demonstrate, over a median treatment duration of 115 weeks, that macitentan at a dose of $10 \mathrm{mg}$ resulted in a $45 \%$ risk reduction $(\mathrm{p}<0.001)$ in the combined primary end-point of morbidity and

\section{TABLE 1 Case studies: shared decision-making}

\section{Patient A}

46-year-old female with IPAH

WHO-FC III, 6MWD $320 \mathrm{~m}$, mRAP $8 \mathrm{mmHg}, \mathrm{mPAP} 56 \mathrm{mmHg}$ and cardiac index $2.6 \mathrm{~L} \cdot \mathrm{min}^{-1} \cdot \mathrm{m}^{-2}$

Rapidly progressive illness

Patient goals: survival at any cost

This patient received rapid sequential subcutaneous treprostinil and PDE5 inhibitor

\section{Patient B}

38-year-old female with scleroderma $\mathrm{PAH}$

WHO-FC III, 6MWD $350 \mathrm{~m}$, mRAP $12 \mathrm{mmHg}, \mathrm{mPAP} 54 \mathrm{mmHg}$ and cardiac index $2.2 \mathrm{~L} \cdot \mathrm{min}^{-1} \cdot \mathrm{m}^{-2}$

Severe right ventricular dilation with severe systolic impairment

Patient goals: to increase exercise capacity and improve symptoms

This patient did not wish to undergo i.v. therapy; she began oral treatment with combined PDE5 inhibitor and ERA. She subsequently deteriorated and was started on i.v. epoprostenol

IPAH: idiopathic pulmonary arterial hypertension (PAH); WHO: World Health Organization; FC: functional class; 6MWD: 6-min walking distance; mRAP: mean right atrial pressure; mPAP: mean pulmonary artery pressure; PDE5: phosphodiesterase type-5; ERA: endothelin receptor antagonist. 


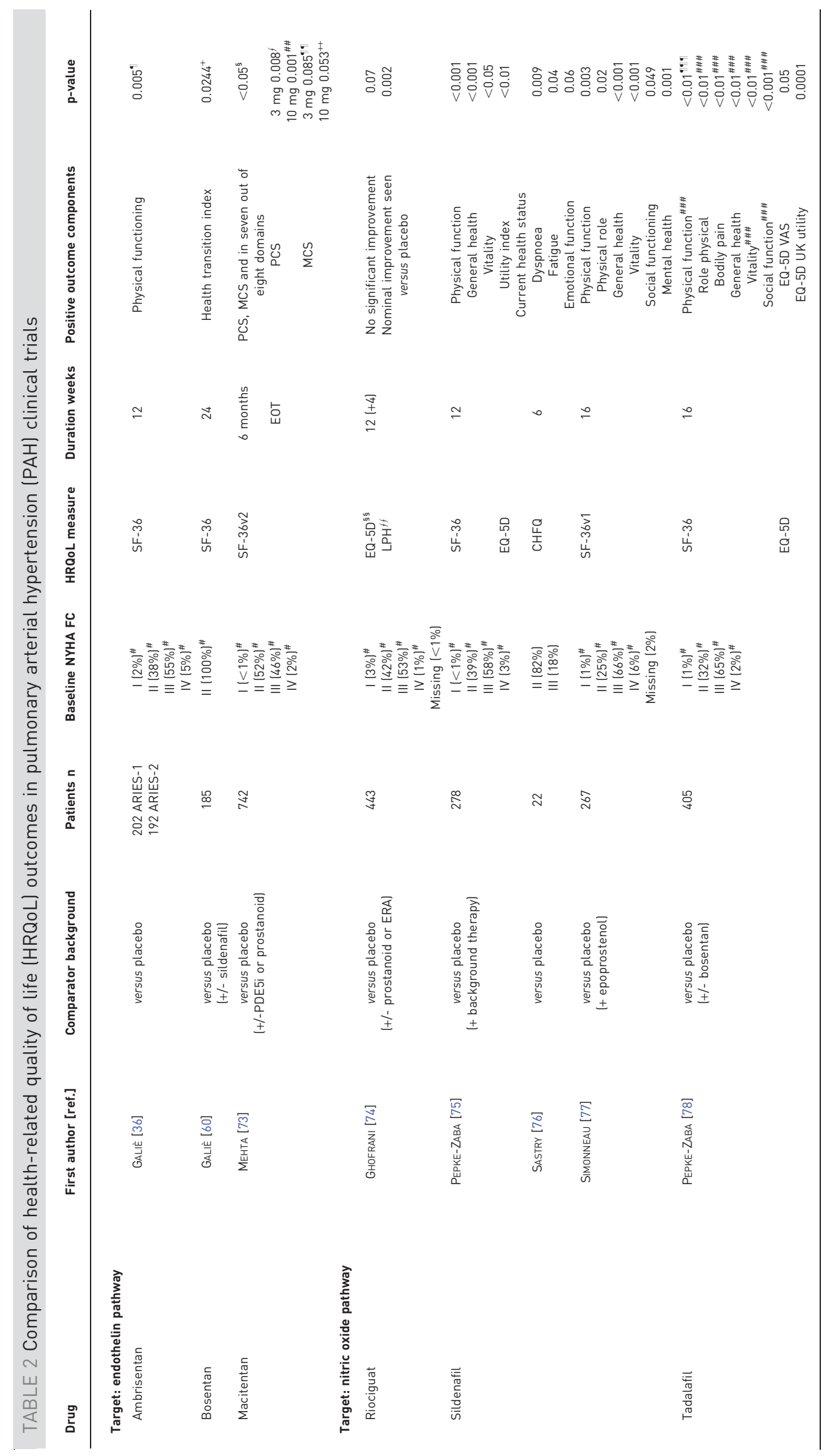




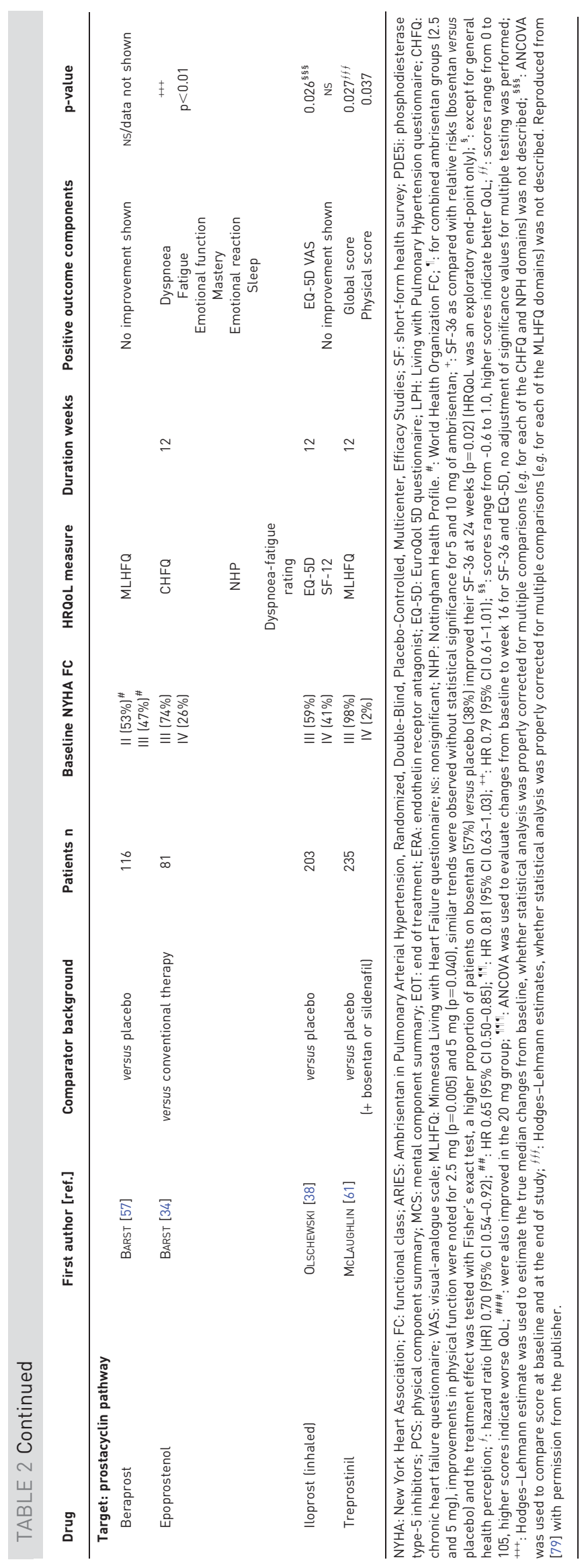


mortality compared with patients taking placebo, of whom $64 \%$ received background PAH therapy and were receiving phosphodiesterase type-5 inhibitors [18]. A similar reduction was observed in a secondary composite end-point of death due to PAH or hospitalisation for PAH [18]. The COMPASS (Effects of Combination of Bosentan and Sildenafil versus Sildenafil Monotherapy on Morbidity and Mortality in Symptomatic Patients with Pulmonary Arterial Hypertension)-2 study evaluated the effect of bosentan in patients with symptomatic PAH already receiving sildenafil therapy [42]. This study was powered to demonstrate a relative risk reduction of $43 \%$ with bosentan versus placebo in the primary end-point of time to the first confirmed morbidity/mortality event. However according to an early release of data, this was not met [43]. More recently, oral selexipag, a selective prostacyclin receptor agonist, has been evaluated in a large phase III trial that aimed to evaluate the time to first morbidity/mortality event, and the primary results have also been released suggesting a positive outcome [44, 45]. With both of these studies, further scrutiny of the data will be required before the licencing agencies and the pulmonary hypertension community can reach any meaningful conclusions. The AMBITION (A Study of First-Line Ambrisentan and Tadalafil Combination Therapy in Subjects with Pulmonary Arterial Hypertension) trial set out to inform on the effect of first-line combination therapy with ambrisentan and tadalafil versus first-line monotherapy with either ambrisentan or tadalafil in patients with PAH using a similar composite endpoint, but which also included an inadequate clinical response as part of the composite end-point [46]. The results have recently been presented at the European Respiratory Society Congress [47] suggesting benefit of upfront combination therapy but, as with the previous studies, full publication is awaited.

By designing studies that have combined morbidity/mortality end-points, the efficacy of the treatment is aligned to treatment outcomes that are important to both patients and physicians. However, the patients' first priority may be that their PAH therapy improves their physical capabilities and HRQoL.

\section{Improving physical functioning}

Functional class assessments

Attainment of modified NYHA/World Health Organization functional class I/II has been deemed to be one of the most important treatment goals [48]. Assessment of NYHA functional class enables patients to be graded by their physicians according to their self-reported limitations on daily physical activities, ranging from no physical impairment (I) to the inability to perform physical activities at rest (IV) [49]. Advanced NYHA functional class in patients with PAH is associated with reduced HRQoL [50], reduced 6MWD [4], and a greater prevalence of anxiety and major depression [51] together with poorer survival [52]. Certain questionnaires have been shown to reflect functional class better; all domains of the Minnesota Living with Heart Failure Questionnaire (MLHFQ), most domains of the Short Form-36 and some components of the Australian Quality of Life tool have been shown to correlate with NYHA functional class [53]. A number of available PAH treatments have shown short-term improvements in NYHA functional class, but typically only in a minority of treated subjects [34-36, 38, 54-57], which have consequently been associated with better long-term outcomes [58].

\section{Exercise capacity}

As a low baseline 6MWD has been linked to a poor long-term prognosis [59], reaching a certain level of exercise capacity is an important goal for the treatment of patients with PAH. Following the 5th World Symposium on Pulmonary Hypertension, it was proposed that a reasonable treatment goal was to increase patients' 6MWD up to $380-440 \mathrm{~m}$, and even higher in young patients, with the rationale that this is associated with better survival. Currently, all available PAH therapies have been shown to improve exercise capacity in the short term (3-6 months) [18, 34-39, 54, 55, 57, 60-63]. Notably, rehabilitation and exercise training, when supervised and coordinated with physiotherapists and other healthcare providers, can also improve exercise capacity $[14,64]$ and endurance capacity [65] in patients with PAH. Although improvement in exercise capacity has been shown to correlate with improvements in haemodynamics [66] and HRQoL [67], the magnitude of change observed in the short-term may not be associated with better long-term outcomes $[68,69]$.

\section{Improving quality of life}

The symptoms of PAH contribute to a reduced overall HRQoL for patients in a similar manner and extent to chronic obstructive pulmonary disease and renal failure [50, 70, 71]. Guidelines resulting from the 4 th and 5th World Symposia on Pulmonary Hypertension stressed the importance of including patientreported outcomes as secondary outcomes in clinical trials of PAH-specific therapies [19, 72]. However, the assessment of results from the use of HRQoL questionnaires is complex, as patient questionnaires cover a broad range of factors, all of which are subjective in nature due to the patient's individual perceptions of their disease and treatment, and due to their physical and mental wellbeing. PAH therapies have shown 
contrasting results in terms of improvements in HRQoL (table 2). These results mostly come from short-term studies with questionnaires that were either developed for use in patient populations with diseases other than $\mathrm{PAH}$, such as the MLHFQ [80], or in mixed patient populations, such as that used to develop the Cambridge Pulmonary Hypertension Outcome Review (CAMPHOR) that included patients with PAH, chronic thromboembolic pulmonary hypertension and other types of pulmonary hypertension [81]. Therefore, care must be taken when interpreting results where such generic questionnaires have been used, given that they lack the specificity needed to address the HRQoL issues that are of importance to patients with PAH [82, 83].

In order to develop questionnaires that are specific to a disease, in this case PAH, the 2009 FDA guidance stated that a patient-reported outcome (PRO) assessment should report on the status of a patient's health condition as directly reported by the patient, without interpretation of the patient's response by a clinician or anyone else [84]. A few questionnaires have been developed in accordance with the requirements from this guidance; however, the PAH-SYMPACT tool has been developed with the FDA PRO guidance in mind and this PAH-specific tool is currently the subject of psychometric validation studies [85-88].

Using appropriate PRO tools should allow for a more robust assessment of PAH therapies in terms of their potential to improve HRQoL and issues of considerable importance to patients with PAH. Improving HRQoL for patients with PAH can, in some way, also be addressed by optimising PAH therapeutic regimens; however, other specialties addressing the physical, mental and social consequences of symptoms in patient care contribute as well. Therefore, it is necessary to combine resources to achieve a comprehensive approach to treatment for this disease.

\section{Multidisciplinary strategies for PAH management}

Living with PAH clearly impacts several areas of patients' lives. Management of patients with PAH would be better served by a multidisciplinary approach that ideally includes healthcare experts to address their needs regarding physical support, as well as mental and social care. This represents a similar multidisciplinary approach to care as required for patients with other chronic diseases such as cystic fibrosis, asthma, heart failure or cancer [89-92]. Moreover, a similar multidisciplinary approach is often the standard of care for patients with $\mathrm{PAH}$ being considered for, or undergoing, lung transplantation. Ideally, patient support teams would be accessed according to the needs of the individual and could include nursing support, physiotherapists, occupational therapists, patient support organisations and social workers to improve patient care greatly. To this end, patient associations provide valuable additional resources for care and support for both patient and caregiver and play a key role in helping patients cope with the financial, social and emotional aspects of PAH (i.e. Pulmonary Hypertension Association of Canada, Pulmonary Hypertension Association UK, Pulmonary Hypertension Association USA and the European Pulmonary Hypertension Association (PHA Europe)).

To deliver this, designated experts would be best placed to provide coordinated clinical practice and care for patients with $\mathrm{PAH}$, while providing advice for physicians who are not specialists in pulmonary hypertension $[93,94]$. In addition, the needs of those who care for patients with PAH are currently underestimated and frequently overlooked. Caregivers are often relatives of the patient and, as such, have their own need for information concerning the care of their loved one, together with a need for emotional support to enable them to cope with the consequences of caring for someone with $\mathrm{PAH}$ on their own lives, in terms of restrictions on their ability to travel, to maintain full-time employment, and the impact on their social and emotional well-being. Therefore, the needs of the caregiver should be assessed as part of the patient's multidisciplinary package of care.

\section{Conclusion}

Key clinical goals for the treatment and management of PAH include delaying disease progression in the long term and achieving treatment goals that improve HRQoL for patients in the short term. However, within this framework, the expectations of physicians and patients are not always aligned in terms of priorities. Physicians need to draw on their clinical expertise and available research in order to provide individualised therapeutic strategies and treatment goals for their patients. Although it may be that patients' wishes cannot always be met, shared decision-making is key to aligning patient and physician expectations. Multidisciplinary healthcare strategies that combine primary pharmacological care from physicians together with care, information and support from a range of sources, including patient associations, physiotherapists and social workers, are vital in order to provide a fully comprehensive approach to caring for patients with $\mathrm{PAH}$.

\section{Acknowledgements}

Medical writing support was provided by Lynda McEvoy (apothecom scopemedical ltd, Sevenoaks, UK), which was funded by Actelion Pharmaceuticals Ltd (Allschwil, Switzerland). 


\section{References}

Hoeper MM, Bogaard HJ, Condliffe R, et al. Definitions and diagnosis of pulmonary hypertension. J Am Coll Cardiol 2013; 62: D42-D50.

2 Galiè N, Torbicki A, Barst R, et al. Guidelines on diagnosis and treatment of pulmonary arterial hypertension. The Task Force on Diagnosis and Treatment of Pulmonary Arterial Hypertension of the European Society of Cardiology. Eur Heart J 2004; 25: 2243-2278.

3 Ling Y, Johnson MK, Kiely DG, et al. Changing demographics, epidemiology, and survival of incident pulmonary arterial hypertension: results from the pulmonary hypertension registry of the United Kingdom and Ireland. Am J Respir Crit Care Med 2012; 186: 790-796.

4 Humbert M, Sitbon O, Chaouat A, et al. Pulmonary arterial hypertension in France: results from a national registry. Am J Respir Crit Care Med 2006; 173: 1023-1030.

5 Benza RL, Miller DP, Barst RJ, et al. An evaluation of long-term survival from time of diagnosis in pulmonary arterial hypertension from the REVEAL Registry. Chest 2012; 142: 448-456.

6 Simonneau G, Gatzoulis MA, Adatia I, et al. Updated clinical classification of pulmonary hypertension. J Am Coll Cardiol 2013; 62: D34-D41.

Purcell H. Moving forward in pulmonary arterial hypertension. Br J Cardiol 2009; 16: Suppl. 1, S2-S3.

Hackman AM, Lackner TE. Pharmacotherapy for idiopathic pulmonary arterial hypertension during the past 25 years. Pharmacotherapy 2006; 26: 68-94.

9 Peacock AJ, Murphy NF, McMurray JJ, et al. An epidemiological study of pulmonary arterial hypertension. Eur Respir J 2007; 30: 104-109.

10 Frost AE, Badesch DB, Barst RJ, et al. The changing picture of patients with pulmonary arterial hypertension in the United States: how REVEAL differs from historic and non-US Contemporary Registries. Chest 2011; 139: 128-137.

11 Escribano-Subias P, Blanco I, López-Meseguer M, et al. Survival in pulmonary hypertension in Spain: insights from the Spanish registry. Eur Respir J 2012; 40: 596-603.

12 Jansa P, Channick R, Delcroix M, et al. Impact of macitentan on the health-related quality of life (HRQoL) in pulmonary arterial hypertension (PAH): results from a long-term randomised controlled trial. Eur Respir J 2013; 42: Suppl. 57, p4075.

13 Gaine SP, Rubin LJ. Primary pulmonary hypertension. Lancet 1998; 352: 719-725.

14 Galiè N, Corris PA, Frost A, et al. Updated treatment algorithm of pulmonary arterial hypertension. J Am Coll Cardiol 2013; 62: D60-D72.

15 Humbert M, Yaïci A, de Groote P, et al. Screening for pulmonary arterial hypertension in patients with systemic sclerosis: clinical characteristics at diagnosis and long-term survival. Arthritis Rheum 2011; 63: 3522-3530.

16 McGoon MD, Miller DP. REVEAL: a contemporary US pulmonary arterial hypertension registry. Eur Respir Rev 2012; 21: 8-18.

17 Humbert M, Sitbon O, Yaïci A, et al. Survival in incident and prevalent cohorts of patients with pulmonary arterial hypertension. Eur Respir J 2010; 36: 549-555.

18 Pulido T, Adzerikho I, Channick RN, et al. Macitentan and morbidity and mortality in pulmonary arterial hypertension. N Engl J Med 2013; 369: 809-818.

19 McLaughlin VV, Badesch DB, Delcroix M, et al. End points and clinical trial design in pulmonary arterial hypertension. J Am Coll Cardiol 2009; 54: Suppl. 1, S97-S107.

20 US Food and Drug Administration. The voice of the patient: a series of reports from the FDA's patient-focused drug development initiative. www.fda.gov/ForIndustry/UserFees/PrescriptionDrugUserFee/ucm368342.htm Date last updated: June 27, 2014. Date accessed: August 28, 2014.

21 Guillevin L, Armstrong I, Aldrighetti R, et al. Understanding the impact of pulmonary arterial hypertension on patients' and carers' lives. Eur Respir Rev 2013; 22: 535-542.

22 The impact of pulmonary arterial hypertension $(\mathrm{PAH})$ on the lives of patients and carers: results from an international survey. www.phaeurope.org/wp-content/uploads/PAH_Survey_FINAL.pdf Date last updated: September 2012. Date last accessed: September 30, 2014.

23 US Food and Drug Administration. Public meeting on pulmonary arterial hypertension patient focused drug development. www.fda.gov/forindustry/userfees/prescriptiondruguserfee/ucm379694.htm Date last updated: June 13, 2014. Date last accessed: August 28, 2014.

24 The Canadian Agency for Drugs and Technologies in Health. Drugs for pulmonary arterial hypertension. www. cadth.ca/en/products/therapeutic-reviews/pulmon-art-hypert Date last updated: 2014. Date last accessed: August 28, 2014.

25 Péloquin J, Robichaud-Ekstrand S, Pepin J. La perception de la qualité de vie de femmes souffrant d'hypertension pulmonaire primaire au stade III ou IV et recevant un traitement á la prostacycline [Quality of life perception by women suffering from stage III or IV primary pulmonary hypertension and receiving prostacyclin treatment]. Can J Nurs Res 1998; 30: 113-136.

26 Joosten EA, DeFuentes-Merillas L, de Weert GH, et al. Systematic review of the effects of shared decision-making on patient satisfaction, treatment adherence and health status. Psychother Psychosom 2008; 77: 219-226.

27 McGoon MD, Kane GC. Pulmonary hypertension: diagnosis and management. Mayo Clin Proc 2009; 84: 191-207.

28 Preston IR, Suissa S, Humbert M. New perspectives in long-term outcomes in clinical trials of pulmonary arterial hypertension. Eur Respir Rev 2013; 22: 495-502.

29 Snow JL, Kawut SM. Surrogate end points in pulmonary arterial hypertension: assessing the response to therapy. Clin Chest Med 2007; 28: 75-89.

30 Kirson NY, Birnbaum HG, Ivanova JI, et al. Excess costs associated with patients with pulmonary arterial hypertension in a US privately insured population. Appl Health Econ Health Policy 2011; 9: 293-303.

31 Channick RN, Delcroix M, Galiè N, et al. Reduction of pulmonary arterial hypertension (PAH)-related hospitalizations with macitentan in the randomized controlled trial SERAPHIN. Value Health 16: 2013; A231. Sitbon O, Morrell N. Pathways in pulmonary arterial hypertension: the future is here. Eur Respir Rev 2012; 21: 321-327. Simonneau G, Robbins IM, Beghetti M, et al. Updated clinical classification of pulmonary hypertension. J Am Coll Cardiol 2009; 54: Suppl. 1, S43-S54. 
34 Barst RJ, Rubin LJ, Long WA, et al. A comparison of continuous intravenous epoprostenol (prostacyclin) with conventional therapy for primary pulmonary hypertension. N Engl J Med 1996; 334: 296-301.

35 Rubin LJ, Badesch DB, Barst RJ, et al. Bosentan therapy for pulmonary arterial hypertension. N Engl J Med 2002; 346: 896-903.

36 Galiè N, Olschewski H, Oudiz RJ, et al. Ambrisentan for the treatment of pulmonary arterial hypertension: results of the ambrisentan in pulmonary arterial hypertension, randomized, double-blind, placebo-controlled, multicenter, efficacy (ARIES) study 1 and 2. Circulation 2008; 117: 3010-3019.

37 Galiè N, Brundage BH, Ghofrani HA, et al. Tadalafil therapy for pulmonary arterial hypertension. Circulation 2009; 119: 2894-2903.

38 Olschewski H, Simonneau G, Galiè N, et al. Inhaled iloprost for severe pulmonary hypertension. N Engl J Med 2002; 347: 322-329.

39 Simonneau G, Barst RJ, Galiè N, et al. Continuous subcutaneous infusion of treprostinil, a prostacyclin analogue, in patients with pulmonary arterial hypertension: a double-blind, randomized, placebo-controlled trial. Am J Respir Crit Care Med 2002; 165: 800-804.

40 Galiè N, Manes A, Negro L, et al. A meta-analysis of randomized controlled trials in pulmonary arterial hypertension. Eur Heart J 2009; 30: 394-403.

41 Macchia A, Marchioli R, Tognoni G, et al. Systematic review of trials using vasodilators in pulmonary arterial hypertension: why a new approach is needed. Am Heart J 2010; 159: 245-257.

42 Clinical trials.gov. Effects of the combination of bosentan and sildenafil versus sildenafil monotherapy on pulmonary arterial hypertension (PAH) (Compass-2). NCT00303459. http://clinicaltrials.gov/show/NCT00303459 Date last updated: February 11, 2014. Date last accessed: August 28, 2014.

43 Actelion. Actelion provides an update on the bosentan study - COMPASS 2. wwwl.actelion.com/en/investors/ news-archive/index.page?newsId=1769001 Date last updated: September 24, 2014. Date last accessed: August 28, 2014.

44 Clinical trials.gov. Selexipag (ACT-293987) in Pulmonary Arterial Hypertension, GRIPHON Trial. NCT01106014. http://clinicaltrials.gov/show/NCT01106014 Date last updated: September 25, 2014. Date last accessed: August 28, 2014.

45 Actelion. Selexipag. www1.actelion.co.uk/sites/en/scientists/development-pipeline/phase-3/selexipag.page Date last updated: September 24, 2014. Date last accessed: August 28, 2014.

46 Clinical trials.gov. A study of first-line ambrisentan and tadalafil combination therapy in subjects with pulmonary arterial hypertension (PAH) (AMBITION). NCT01178073. http://clinicaltrials.gov/show/NCT01178073 Date last updated: October 2, 2014. Date last accessed August 28, 2014

47 Galiè N. The AMBITION study: design and results. Eur Respir J 2014; 44: Suppl. 58, p2916.

48 McLaughlin VV, Gaine SP, Howard LS, et al. Treatment goals of pulmonary hypertension. J Am Coll Cardiol 2013; 62: D73-D81.

49 New York Heart Association. Classification of functional capacity and objective assessment. http://my. americanheart.org/professional/StatementsGuidelines/ByPublicationDate/PreviousYears/Classification-of-FunctionalCapacity-and-Objective-Assessment_UCM_423811_Article.jsp Date last updated: 1994. Date last accessed: August 28, 2014.

50 Taichman DB, Shin J, Hud L, et al. Health-related quality of life in patients with pulmonary arterial hypertension. Respir Res 2005; 6: 92.

51 Lowe B, Gräfe K, Ufer C, et al. Anxiety and depression in patients with pulmonary hypertension. Psychosom Med 2004; 66: 831-836.

52 Humbert M, Sitbon O, Chaouat A, et al. Survival in patients with idiopathic, familial, and anorexigen-associated pulmonary arterial hypertension in the modern management era. Circulation 2010; 122: 156-163.

53 Chua R, Keogh AM, Byth K, et al. Comparison and validation of three measures of quality of life in patients with pulmonary hypertension. Intern Med J 2006; 36: 705-710.

54 Galiè N, Ghofrani AH. New horizons in pulmonary arterial hypertension therapies. Eur Respir Rev 2013; 22: 503-514.

55 Channick RN, Simonneau G, Sitbon O, et al. Effects of the dual endothelin-receptor antagonist bosentan in patients with pulmonary hypertension: a randomised placebo-controlled study. Lancet 2001; 358: 1119-1123.

56 Galiè N, Ghofrani HA, Torbicki A, et al. Sildenafil citrate therapy for pulmonary arterial hypertension. $N$ Engl J Med 2005; 353: 2148-2157.

57 Barst RJ, McGoon M, McLaughlin V, et al. Beraprost therapy for pulmonary arterial hypertension. J Am Coll Cardiol 2003; 41: 2119-2125.

58 Barst RJ, Chung L, Zamanian RT, et al. Functional class improvement and 3-year survival outcomes in patients with pulmonary arterial hypertension in the REVEAL Registry. Chest 2013; 144: 160-168.

59 Groepenhoff H, Vonk-Noordegraaf A, van de Veerdonk MC, et al. Prognostic relevance of changes in exercise test variables in pulmonary arterial hypertension. PLoS One 2013; 8: e72013.

60 Galiè N, Rubin L, Hoeper M, et al. Treatment of patients with mildly symptomatic pulmonary arterial hypertension with bosentan (EARLY study): a double-blind, randomised controlled trial. Lancet 2008; 371: 2093-2100.

61 McLaughlin VV, Benza RL, Rubin LJ, et al. Addition of inhaled treprostinil to oral therapy for pulmonary arterial hypertension: a randomized controlled clinical trial. J Am Coll Cardiol 2010; 55: 1915-1922.

62 Galiè N, Humbert M, Vachiéry JL, et al. Effects of beraprost sodium, an oral prostacyclin analogue, in patients with pulmonary arterial hypertension: a randomized, double-blind, placebo-controlled trial. J Am Coll Cardiol 2002; 39: $1496-1502$.

63 Rubin LJ, Mendoza J, Hood M, et al. Treatment of primary pulmonary hypertension with continuous intravenous prostacyclin (epoprostenol). Results of a randomized trial. Ann Intern Med 1990; 112: 485-491.

64 Mereles D, Ehlken N, Kreuscher S, et al. Exercise and respiratory training improve exercise capacity and quality of life in patients with severe chronic pulmonary hypertension. Circulation 2006; 114: 1482-1489.

65 de Man FS, Handoko ML, Groepenhoff $\mathrm{H}$, et al. Effects of exercise training in patients with idiopathic pulmonary arterial hypertension. Eur Respir J 2009; 34: 669-675.

66 Savarese G, Musella F, D'Amore C, et al. Haemodynamics, exercise capacity and clinical events in pulmonary arterial hypertension. Eur Respir J 2013; 42: 414-424. 
Mathai SC, Puhan MA, Lam D, et al. The minimal important difference in the 6-minute walk test for patients with pulmonary arterial hypertension. Am J Respir Crit Care Med 2012; 186: 428-433.

68 Gaine S, Simonneau G. The need to move from 6-minute walk distance to outcome trials in pulmonary arterial hypertension. Eur Respir Rev 2013; 22: 487-494.

69 Fritz JS, Blair C, Oudiz RJ, et al. Baseline and follow-up 6-min walk distance and brain natriuretic peptide predict 2-year mortality in pulmonary arterial hypertension. Chest 2013; 143: 315-323.

70 Harper R, Brazier JE, Waterhouse JC, et al. Comparison of outcome measures for patients with chronic obstructive pulmonary disease (COPD) in an outpatient setting. Thorax 1997; 52: 879-887.

71 Wight JP, Edwards L, Brazier J, et al. The SF36 as an outcome measure of services for end stage renal failure. Qual Health Care 1998; 7: 209-221.

72 Gomberg-Maitland M, Bull TM, Saggar R, et al. New trial designs and potential therapies for pulmonary artery hypertension. J Am Coll Cardiol 2013; 62: D82-D91.

73 Mehta S, Channick R, Delcroix M, et al. Macitentan improves health-related quality of life in pulmonary arterial hypertension: results from the randomized controlled SERAPHIN trial. Am J Respir Crit Care Med 2013; 187: A3269.

74 Ghofrani HA, Galiè N, Grimminger F, et al. Riociguat for the treatment of pulmonary arterial hypertension. $N$ Engl J Med 2013; 369: 330-340.

75 Pepke-Zaba J, Gilbert C, Collings L, et al. Sildenafil improves health-related quality of life in patients with pulmonary arterial hypertension. Chest 2008; 133: 183-189.

76 Sastry BK, Narasimhan C, Reddy NK, et al. Clinical efficacy of sildenafil in primary pulmonary hypertension: a randomized, placebo-controlled, double-blind, crossover study. J Am Coll Cardiol 2004; 43: 1149-1153.

77 Simonneau G, Rubin LJ, Galiè N, et al. Addition of sildenafil to long-term intravenous epoprostenol therapy in patients with pulmonary arterial hypertension: a randomized trial. Ann Intern Med 2008; 149: 521-530.

78 Pepke-Zaba J, Beardsworth A, Chan M, et al. Tadalafil therapy and health-related quality of life in pulmonary arterial hypertension. Curr Med Res Opin 2009; 25: 2479-2485.

79 Rival G, Lacasse Y, Martin S, et al. Effect of pulmonary arterial hypertension-specific therapies on health-related quality of life: a systematic review. Chest 2014; 146: 686-708.

80 Rector TS, Cohn JN. Assessment of patient outcome with the Minnesota Living with Heart Failure questionnaire: reliability and validity during a randomized, double-blind, placebo-controlled trial of pimobendan. Pimobendan Multicenter Research Group. Am Heart J 1992; 124: 1017-1025.

81 McKenna SP, Doughty N, Meads DM, et al. The Cambridge Pulmonary Hypertension Outcome Review (CAMPHOR): a measure of health-related quality of life and quality of life for patients with pulmonary hypertension. Qual Life Res 2006; 15: 103-115.

82 Rubenfire M, Lippo G, Bodini BD, et al. Evaluating health-related quality of life, work ability, and disability in pulmonary arterial hypertension: an unmet need. Chest 2009; 136: 597-603.

83 Chen H, Taichman DB, Doyle RL. Health-related quality of life and patient-reported outcomes in pulmonary arterial hypertension. Proc Am Thorac Soc 2008; 5: 623-630.

84 US Food and Drug Administration. Guidance for Industry - Patient-reported outcome measures: use in medical product development to support labeling claims. www.fda.gov/downloads/Drugs/Guidances/UCM193282.pdf Date last updated: December 2009. Date last accessed: August 28, 2014.

85 McCollister D, Kummer S, Badesch DB, et al. Development of the pulmonary arterial hypertension - symptoms and Impact (PAH-SYMPACT ${ }^{\mathrm{TM}}$ ) questionnaire: a new disease-specific patient-reported outcome instrument for PAH. Am J Respir Crit Care Med 2013; 187: A3294.

86 Clinical trials.gov. SYMPHONY: A study of macitentan in pulmonary arterial hypertension to validate the PAHSYMPACT. NCT01841762. http://clinicaltrials.gov/show/NCT01841762 Date last updated: September 18, 2014. Date last accessed: August 28, 2014.

87 Clinical trials.gov. A Pulmonary Arterial Hypertension Study With Macitentan to Validate the PAH-SYMPACT ${ }^{\mathrm{TM}}$ in France, Italy and Spain (ORCHESTRA). NCT02081690. http://clinicaltrials.gov/show/NCT02081690 Date last updated: August 7, 2014. Date last accessed: August 28, 2014.

88 Clinical trials.gov. Extension of the Psychometric Validation Study ORCHESTRA in Patients with PAH. NCT02112487. http://clinicaltrials.gov/show/NCT02112487 Date last updated: August 11, 2014. Date last accessed: August 28, 2014

89 Mahadeva R, Webb K, Westerbeek RC, et al. Clinical outcome in relation to care in centres specialising in cystic fibrosis: cross sectional study. BMJ 1998; 316: 1771-1775.

90 Lamb BW, Sevdalis N, Mostafid H, et al. Quality improvement in multidisciplinary cancer teams: an investigation of teamwork and clinical decision-making and cross-validation of assessments. Ann Surg Oncol 2011; 18: 3535-3543.

91 McAlister FA, Stewart S, Ferrua S, et al. Multidisciplinary strategies for the management of heart failure patients at high risk for admission: a systematic review of randomized trials. J Am Coll Cardiol 2004; 44: 810-819.

92 Chan DS, Callahan CW, Moreno C. Multidisciplinary education and management program for children with asthma. Am J Health Syst Pharm 2001; 58: 1413-1417.

93 National Pulmonary Hypertension Centres of United Kingdom and Ireland Physician's Committee. www. pulmonaryhypertensioncentres.co.uk/who/index.html Date last accessed: August 28, 2014.

94 National Pulmonary Hypertension Centres of the UK and Ireland. Consensus statement on the management of pulmonary hypertension in clinical practice in the UK and Ireland. Thorax 2008; 63: Suppl. 2, ii1-ii41. 